\title{
Hommage artistique ou tentative pionnière de révision historique ? La Guerre d'Indépendance espagnole (1808-1814) au prisme de la série Los Desastres de la Guerra (TV3, 1983)
}

Jean-Marc Lafon

\section{(2) OpenEdition}

\section{Journals}

Édition électronique

URL : http://journals.openedition.org/tvseries/1752

DOI : 10.4000/tvseries. 1752

ISSN : 2266-0909

\section{Éditeur}

GRIC - Groupe de recherche Identités et Cultures

\section{Référence électronique}

Jean-Marc Lafon, « Hommage artistique ou tentative pionnière de révision historique ? La Guerre d'Indépendance espagnole (1808-1814) au prisme de la série Los Desastres de la Guerra (TV3, 1983) », TV/Series [En ligne], 10 | 2016, mis en ligne le 01 décembre 2016, consulté le 14 novembre 2019. URL : http://journals.openedition.org/tvseries/1752; DOI : 10.4000/tvseries.1752

Ce document a été généré automatiquement le 14 novembre 2019.

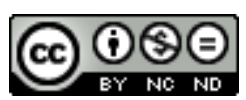

TV/Series est mis à disposition selon les termes de la licence Creative Commons Attribution - Pas d'Utilisation Commerciale - Pas de Modification 4.0 International. 


\title{
Hommage artistique ou tentative
} pionnière de révision historique? La Guerre d'Indépendance espagnole (1808-1814) au prisme de la série Los Desastres de la Guerra (TV3, 1983)

\author{
Jean-Marc Lafon
}

1 Cette mini-série historique ${ }^{1}$ - en 6 épisodes, pour une durée totale de près de 6 heures fut un ambitieux projet de TVE (un budget de 300 millions de pesetas ${ }^{2}$, soit $1803036 €$ actuels), destiné à raconter la guerre d'Indépendance espagnole (1808-1814) à travers les yeux de l'artiste qui en fut l'un des principaux témoins : Francisco de Goya. Portant le titre du cycle de gravures le plus connu du peintre, entré dans l'histoire pour sa représentation crue des horreurs de la guerre, Los Desastres de la guerra fut confié au scénariste et cinéaste Mario Camus (qui venait d'être récompensé en 1982 par l'Ours d'Or du Festival de Berlin pour La Ruche, adaptation du roman de Camilo José Cela). De plus, l'intellectuel engagé Jorge Semprún, rescapé de Buchenwald, collaborateur de Costa-Gavras ou Yves Boisset, participa à l'écriture du scénario, avec Rafael Azcona et Eduardo Chamorro. La revue Teleradio, dans son numéro 1316 (18-24 mars 1983), l'annonça comme "l'événement télévisuel de l'année ${ }^{3}$ ».

2 La série fut tournée durant l'été et l'automne 1982, entièrement en décors naturels, profitant de sites espagnols classés comme le Palais Royal madrilène, l'ensemble palatial de La Granja de San Ildefonso, l'enceinte fortifiée d'Avila ou le centre historique de Cordoue, ainsi que de paysages «naturels " préservés des provinces de Guadalajara et Ciudad Real... Elle bénéficia de la présence d'un trio de comédiens renommés : Francisco Rabal, l'un des acteurs fétiches de Buñuel dans le rôle de Goya, et les Français 
Pierre Santini (Napoléon) et Bernard Fresson (le général Hugo); l'ensemble de sa distribution s'avérait conséquent, incluant 156 acteurs et 5 actrices.

Los Desastres... fut d'abord diffusée en Espagne, entre juin et juillet 1983 sur TV3, puis en France, en février/mars 1984, en début de soirée sur Antenne 2 sous un titre légèrement modifié, Guérilla ou les désastres de la guerre. Il s'agit de la première coproduction hispano-française ( $51 \%$ de financement espagnol, $49 \%$ français) sur un sujet épineux: l'invasion inattendue par Napoléon d'un pays allié, qui remplaça la dynastie régnante par son frère aîné Joseph, prélude à une guerre interminable et marquée d'atrocités réciproques. Le discours s'efforce dès lors d'éviter tout manichéisme, alors qu'il traite d'un moment fondateur: l'entrée traumatisante de l'Espagne dans la contemporanéité ${ }^{4}$. Jusqu'alors il avait été traité en Espagne selon une perspective héroïsante, à la fois folklorique et nationaliste. En revanche, il restait quasiment ignoré par le cinéma français ${ }^{5}$, si l'on excepte l'évidente résurgence de la Leyenda negra (la "légende noire ») dans une production mineure, inspirée par les romans à succès de Cecil Saint-Laurent (l'un des nombreux pseudonymes de Jacques Laurent), Le Fils de Caroline chérie (Jean Devaivre, 1955).

Cette mini-série est également la première évocation d'ensemble $\mathrm{du}$ conflit, manifestant une nette volonté pédagogique, depuis les préparatifs du guet-apens de Bayonne au printemps 1808, jusqu'à la défaite impériale décisive de Vitoria (21 juin 1813) et au rétablissement de l'absolutisme par Ferdinand VII (mai 1814). Le cadre de l'action souligne cependant la prédominance des deux Castilles, théâtre de l'affrontement récurrent de Juan Martín Díez l'Empecinado (« l'obstiné ») et du général Hugo, et siège - passablement instable et précaire - du pouvoir de Joseph Bonaparte ${ }^{6}$.

5 Le récit prétend à "l'histoire totale ", à la fois diplomatique, militaire et politique, même si la dimension sociale du conflit reste seulement ébauchée. Pour cela, les scénaristes ont utilisé des sources nombreuses et variées, minutieusement recensées par Jesús Maroto dans un ouvrage de référence ${ }^{7}$ : les mémoires de Constant, le valet de Napoléon, de l'abbé de Pradt, du chanoine Escoiquiz, conseiller de Ferdinand VII, du général Hugo, « le héros au sourire si doux », mais aussi les souvenirs de son fils Victor retranscrits par sa femme Adèle Foucher, la correspondance de Napoléon, ou encore la presse officielle espagnole (qui donne lieu à plusieurs scènes de lecture publique, environ $94 \%$ de la population étant alors analphabète). L'iconographie goyesque occupe logiquement une place de premier plan, notamment les Desastres de la guerra à l'origine du titre, 82 estampes gravées entre 1810 et 1820 mais publiées seulement en 1863, de manière posthume. Mais la série mobilise de nombreuses autres œuvres du peintre aragonais, selon un choix significatif.

6 Le programme s'inscrit en outre dans une phase de transition historiographique signant la fin du monopole national-catholique ${ }^{8}$ : entre la séquence libérale, voire « marxisante » du franquisme technocratique, notamment incarnée par Miguel Artola qui dépeint le peuple espagnol comme uni contre l'envahisseur français, et avant le tournant révisionniste qui nuance l'union national(ist)e espagnole. Ce revirement est impulsé par plusieurs auteurs anglo-saxons à la fin des années 1980, principalement autour des thèmes connexes de la guérilla et de la contre-guérilla, pour la première fois soumis à une lecture critique qui complexifie la compréhension du camp des «bons » et des « méchants ", en insistant sur le rôle déterminant de l'Angleterre, l'existence d'une fraction de la population espagnole favorable aux Français par désir de démocratie et de réformes, et le soutien d'un clergé fanatique aux guérilleros ${ }^{9}$. Cette approche est 
relayée en Espagne par les travaux du politiste José Álvarez Junco à partir de $1994^{10}$, et les liens avec la guerre civile de 1936 ne sont évidemment pas fortuits.

7 Enfin, c'est la première fois qu'une telle place est accordée à Goya dans le récit de ce conflit. Certes, c'était déjà un personnage cinématographique récurrent, apparaissant dans au moins six films espagnols, un américain, un est-allemand, et un épisode d'une série espagnole antérieurs ${ }^{11}$, outre deux tentatives avortées de Buñuel en 1926 et 1937. Mais cette série contribue indéniablement à renforcer son rôle de protagoniste et pas seulement de témoin des événements. Il sera ainsi peu après l'objet d'une série éponyme italo-espagnole en 1984, puis de films de Carlos Saura (Goya en Burdeos, 1999) et Juan José Bigas Luna (Volaverunt, 1999) et enfin d'une très décevante fresque hollywoodienne (Les Fantômes de Goya, Milos Forman, 2006) ${ }^{12}$.

8 L'homme n'est plus dès lors un personnage secondaire ou le sujet d'anecdotes faciles du fait de ses amours tumultueuses avec la duchesse d'Albe, mais bien l'homme pluridimensionnel qui apparaît ici : l'homme privé, l'artiste officiel - peintre de cour de Charles IV depuis 1789, confirmé par Joseph Bonaparte puis rétabli dans sa charge par Ferdinand IV en 1814 -, ainsi que l'artiste pour soi (ayant choisi de se soustraire à la demande sociale pour toute une partie de son œuvre), le penseur autodidacte et l'acteur politique révélés par des essais récents ${ }^{13}$. Cela lui confère un statut d'exception pour la représentation du conflit.

9 Cette série méconnue en France - à l'image du conflit qu'elle met en scène - sera donc abordée sous deux angles complémentaires, l'un esthétique et l'autre historique. Le premier se focalisera sur la place cruciale accordée à Goya comme observateur/ rapporteur du conflit, le second sur les choix épistémologiques du réalisateur et des scénaristes dans le traitement de la guerre à l'écran.

\section{Goya, peintre de guerre, peintre dans la guerre}

L'artiste occupe une place aussi prédominante que centrale dans la narration, ce qui correspond à la fois à son rôle historique et au tournant esthétique qu'il incarne dans la représentation du phénomène guerrier. En effet ses œuvres, et le cycle de gravures Los desastres de la guerra en particulier, ne suivent plus la tradition majoritaire de l'Ancien Régime d'une représentation héroïsée et aseptisée selon ${ }^{14}$, mais en dépeignent toute la cruauté et le nihilisme intrinsèque. Néanmoins, la série reprend aussi l'image mythique du peintre construite à partir de la moitié du XIX siècle par les romantiques européens, de tendance conservatrice comme libérale : un artiste "rebelle » selon le modèle fixé par les mémoires de Benvenuto Cellini, proche du peuple et de ses traditions, incarnant « l'âme espagnole » (individualiste, passionnée et impulsive) ${ }^{15}$.

\section{Echos narratifs et visuels}

Construite autour de Goya, la cohésion interne de la série est réelle, organisée en un complexe système d'échos et de renvois. Ainsi, la procession de l'extrême-onction croisée par l'artiste juste avant le déclenchement du conflit (1.1) fait écho au convoi funéraire de sa femme, Josefa Bayeu, le 20 juin 1812 (1.5); la fuite solitaire de L'Empecinado (Sancho Gracia) à la fin de l'épisode 2 fait écho au le galop collectif de sa troupe (1.4), désormais reconnue et légitimée. Cela renvoie bien sûr aux motifs du western européen, d'autant que la musique chorale créée par Antón García Abril, 
compositeur attitré de Mario Camus, n'est pas sans évoquer les œuvres d'Ennio Morricone pour Sergio Leone ou Sergio Corbucci. Cette structure en écho nuance aussi le propos et la lecture de l'Histoire: si l'épisode 2 est centré sur l'émergence du chef guérillero, le $3^{\mathrm{e}}$ se focalise sur son principal adversaire, le général Hugo, devenu expert de la contre-guérilla depuis ses expériences en Vendée et dans le royaume de Naples.

Comme le montre le tableau synthétique (figure 1), Goya occupe une place centrale dans le récit, par sa personne comme par son œuvre. Pour cette dernière, Mario Camus a su varier les effets: dans les deux premiers épisodes, des ralentis précèdent l'insertion des estampes, permettant de les fusionner dans le déroulement de l'action; en revanche dans les suivants (3 et 4), il recourt à l'élision. S'agissant de cadavres mutilés et profanés, la puissance de sidération des Desastres rend inutile ce redoublement narratif : le spectateur effectue de lui-même le rapprochement. Enfin, le début de l'épisode 5 superpose les séquences des rues endeuillées de Madrid, parcourues de mourants affamés et de charrettes chargées de cadavres, et les visions du peintre sous forme de « reportage » graphique.

Fig. 1 : L'homme et l'artiste Goya, point focal de la série

\begin{tabular}{|l|l|l|l|}
\hline Modes & Séquences & Contenu & Occurrences \\
\hline \multirow{2}{*}{ Oralité } & $\begin{array}{l}\text { Prologue (tirade de } \\
\text { Goya, reproduite infra) } \\
\text { Discussions dans } \\
\text { l'atelier }\end{array}$ & $\begin{array}{l}\text { Morale série? } \\
\text { Ami (1.1); Empecinado (1.2); Marchena } \\
(1.3) ; \text { généraux français (1.4) }\end{array}$ & 4 \\
\hline Gestuelle & $\begin{array}{l}\text { Madrid } \\
\text { Création picturale }\end{array}$ & $\begin{array}{l}\text { Extrême-onction (1.1); enterrement Josefa } \\
(1.5) \\
\text { Sanguine, portrait équestre Ferdinand VII, } \\
\text { ébauche Dos de Mayo (1.1); portrait } \\
\text { général Guye (1.4); portrait Ferdinand VII } \\
(1.6)\end{array}$ & 5 \\
\hline $\begin{array}{l}\text { Références } \\
\text { iconogra- } \\
\text { phiques }\end{array}$ & $\begin{array}{l}\text { Tableaux vivants } \\
\text { Estampes insérées } \\
\text { Elisions } \\
\text { Allusions }\end{array}$ & $\begin{array}{l}\text { Estampes alternées, gros plans et détails } \\
\text { Emeute Dos de Mayo (1.1); fabrication } \\
\text { poudre (1.3) } \\
\text { Prémonition (1.1) Charnier (1.2); famine à } \\
\text { Madrid (1.5) } \\
\text { Cadavres exposés (1.3 et 1.4) } \\
\text { Evasion Empecinado (1.2) }\end{array}$ & 2 \\
\hline Env. 15 \\
3 \\
1
\end{tabular}

De plus, la série est tissée d'échos et de renvois à l'œuvre de Goya : ainsi l'attitude du plaignant, lors de la procession (1.1) aussitôt identifiée à l'estampe source $n^{\circ} 1$ des Desastres (Tristes presentimientos de lo que ha de acontecer, figure 2) annonce la posture christique de la victime centrale du Tres de Mayo. Celle-ci est d'ailleurs accentuée par la révélation récente, suite à la restauration du tableau en 2008 , de la présence d'un stigmate à sa main droite. 
Fig. 2 : Estampe $n^{\circ} 1$ de Los desastres de la guerra, intitulée Tristes presentimientos de lo que ha de acontecer (" Tristes présages de ce qui doit arriver)

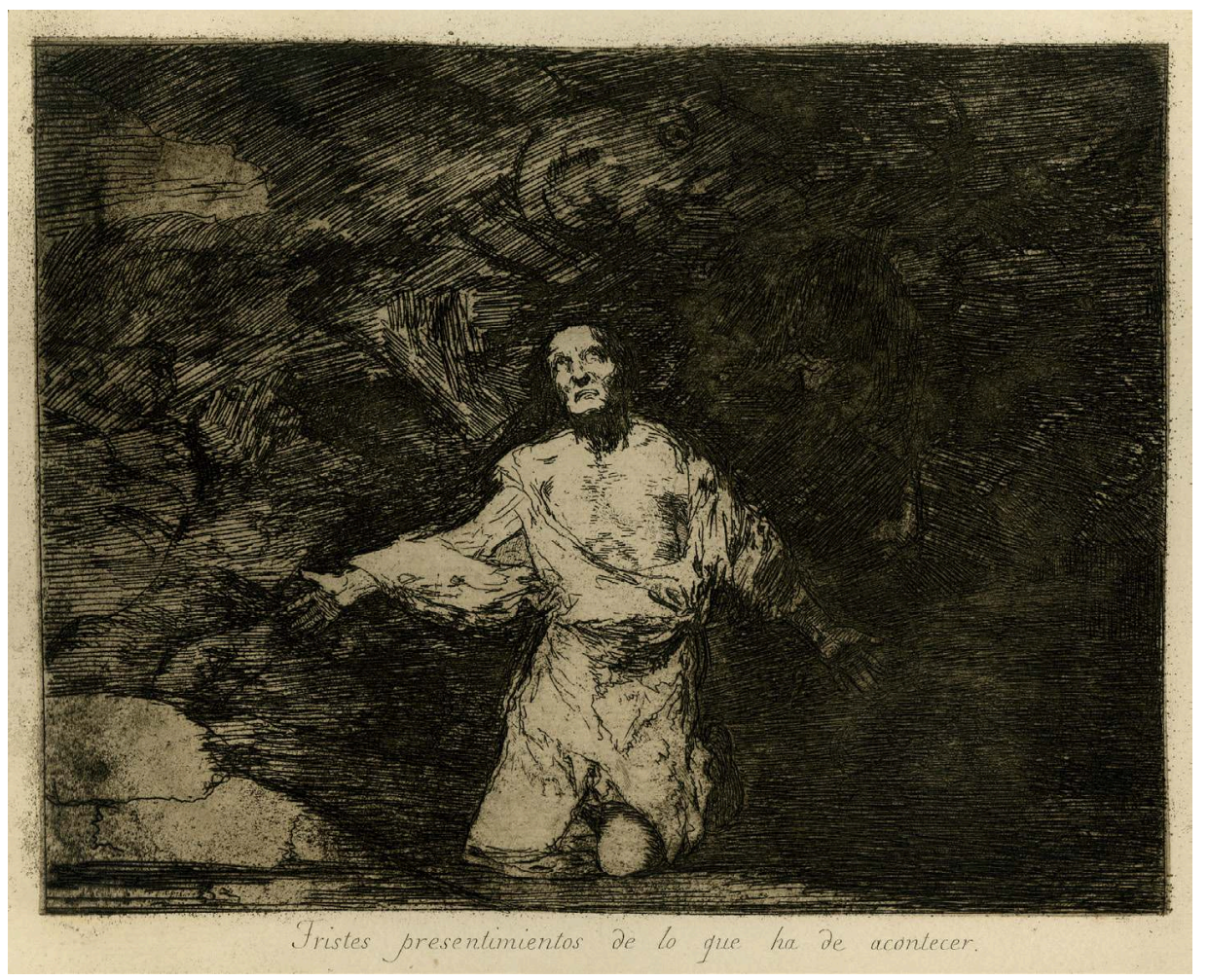

D'autre part, les scènes d'atelier récurrentes permettent de "dévoiler " les mêmes images du conflit à des protagonistes issus de camps différents (le chef de partisans $\mathrm{El}$ Empecinado et Marchena, l'intellectuel afrancesado, c'est-à-dire proche des Français, interprété par Mario Pardo) et de connaître leurs réactions. Elles développent ainsi un récit polyphonique de l'événement, a priori plus objectif.

D'autres images - notamment les frutos franceses (corps suppliciés d'officiers et soldats français, pendus à des arbres) - scandent l'intrigue. Elles soulignent les progrès de la résistance et la nature illusoire de la domination napoléonienne ${ }^{17}$. C'est notamment le cas lors de l'arrivée du convoi de la famille Hugo, dans une Espagne censée avoir été pacifiée (1.4), une scène fictive qui n'apparaît pas dans les souvenirs d'enfance de Victor. Enfin, les estampes 48 à 64 sur la famine madrilène de 1812 sont particulièrement présentes dans l'avant-dernier épisode, avec la succession, sous forme de "récit graphique", de 13 des lithographies consacrées par Goya à ce sujet (soit $76,4 \%$ de ce sous-ensemble des Desastres). L'effet d'horreur est renforcé par la visite du roi Joseph (Philippe Rouleau) dans un hôpital mouroir : la scène est presque muette (l'unique phrase prononcée mentionne le chiffre de 10000 morts dans la capitale), rythmée par les râles, les gémissements et les supplications des agonisants.

16 L'œuvre du peintre montrée au petit écran ne se limite cependant pas à la seule série des Desastres, abondamment citée. Plusieurs allusions vont au-delà, illustrant un souci de réalisme dans la reproduction de la société espagnole du l'orée du XIX siècle. Ainsi, l'emploi d'échasses pour l'évasion du chef guérillero, évocation d'une commande royale de 1791 (un carton d'une série de tapisseries devant décorer le cabinet du roi à

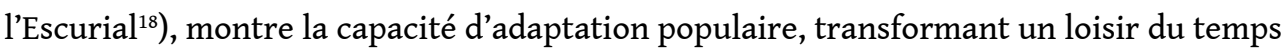
de paix en stratagème inattendu. La séquence de la fabrication «artisanale » de la 
poudre, décalque d'une huile sur bois effectuée durant le conflit (figure 3) est à envisager dans la même perspective.

Fig. 3 : Francisco de Goya, La fabricación de pólvora en la sierra de Tardienta (La fabrication de la poudre dans la Serria de Tardienda), huile sur toile (32,9 x 52,2 cm), Palais de la Zarzuela (Madrid), 1810-1814 (partie gauche de l'œuvre)

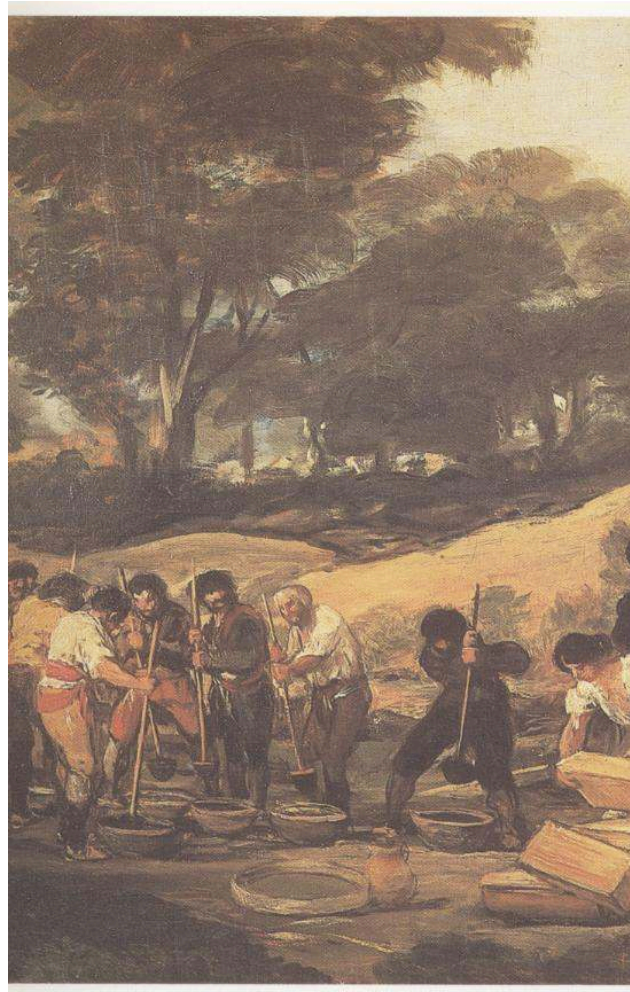

Dès lors, les omissions s'avèrent également révélatrices, comme le confirmera la seconde partie : signalons juste ici la quasi-absence des tableaux iconiques de 1814 (le Dos de Mayo n'apparaît qu'à l'état préliminaire au pastel, comme « brouillon » au 1.2 et en cours d'achèvement au 1.6). De même, la rencontre de Goya avec Wellington durant l'été de 1812, à l'origine du portrait du futur vainqueur de Waterloo, est escamotée : ce dernier occupe pourtant une place non négligeable dans les trois derniers épisodes (neuf séquences). Il est parfois présent de manière indirecte (harangue de Marchena aux guérilleros, lettre « interceptée » du général britannique mentionnant le départ de l'Empecinado pour la Manche, annonce au roi Joseph de la victoire anglo-portugaise aux Arapiles, manifeste arrogant adressé aux madrilènes), mais le plus souvent on le voit en personne : rencontre avec les principaux chefs guérilléros (cabecillas) des deux Castilles, propos sarcastiques sur la Constitution adoptée à Cadix le 19 mars 1812, justification de sa politique de "terre brûlée ", préparatifs de la bataille de Vitoria, honneurs concédés après sa nouvelle victoire. Wellington apparait assez aisément comme "le méchant " de l'histoire : ainsi ne pas montrer sa rencontre avec Goya permet de conforter l'artiste dans son rôle de « visionnaire » du bon côté de l'histoire.

L'usage très modéré des "tableaux vivants " inspirés par l'œuvre goyesque et la neutralité des quelques sujets retenus, généralement documentaires, comme la Fabrique de poudre, attestent une démarche similaire. L'absence du Tres de Mayo, répression brutale et disproportionnée ordonnée par Murat au nom d'un terrorisme d'État prôné par l'Empereur dans les pays conquis ${ }^{19}$, apparaît ici particulièrement significative. En 
revanche, la reconstitution minutieuse des exécutions madrilènes constitue un moment fort - ou vaut-il mieux parler de "passage obligé »? - des films espagnols dédiés au conflit, dès l'origine (El Dos de Mayo, José Buchs, 1927), jusqu'au grand spectacle franquiste Agustina de Aragón ${ }^{20}$ (Juan de Orduña, 1950) ou encore de la série Goya (José Ramon Larraz, 1984), coproduction cette fois hispano-italienne ${ }^{21} \ldots$

En fait, la figure centrale du peintre est sous-tendue par la structure circulaire de l'intrigue. L'Histoire dont il est un observateur privilégié est celle d'une révolution complète, de l'émeute initiale ayant porté Ferdinand VII au pouvoir en mars 1808 à son retour triomphal de captivité en mai 1814 suivi du facile rétablissement de l'absolutisme par ses partisans. Le premier événement est ourdi en coulisses par les complices réactionnaires du Prince héritier, mais concède une certaine initiative au peuple, qui s'amplifiera lors de l'insurrection, avant de disparaitre au profit du statu quo ante... Dans son dernier chantier pictural, significativement, Goya à genoux reprend et parachève le portrait équestre officiel du souverain absolutiste, ébauché au début de la série.

Hantée par ce cercle vicieux sous-jacent, la tonalité d'ensemble de la série s'avère donc pessimiste, sinon nihiliste, conforme à l'image de Goya forgée par les romantiques et les détracteurs des Lumières, et au désenchantement post-moderne de la Movida, arrièrefonds culturel dominant lors de la fabrication du téléfilm de Mario Camus. La meilleure illustration en est la séquence finale, consacrée au devenir de certains des principaux protagonistes (dans l'ordre, Napoléon, Marchena, le général Hugo, le roi Joseph, l' Empecinado et Goya lui-même ${ }^{22}$ ). Leur échec individuel dans la péninsule traduit le naufrage de l'Espagne, livrée dans les dernières scènes au fanatisme de la plèbe urbaine - qui a triomphé du peuple rural héroïque et laborieux (représenté par l'Empecinado et son second García, interprété par Manuel Zarzo) - et à la paranoïa de Ferdinand VII (Francisco Cecilio), à son obsession du pouvoir absolu :

FERDINAND VII. Je dois penser à l'Espagne, aux Indes. De partout peut surgir un nouvel ennemi, ou réapparaître un ancien ennemi.

GÉNÉRAL ELIO. S'agissant de l'Espagne, vous pouvez être tranquille, Votre Majesté. Les prisons sont pleines de libéraux, d'afrancesados, et d'individus hostiles à la monarchie. [...] Mais les juges posent problème : ils prétendent qu'on ne peut juger les opinions, ni les intentions.

FERDINAND VII. Les magistrats ne peuvent juger les opinions. C'est logique, ce ne sont que des sujets, ils sont donc ignorants. Ils ne connaissent pas la méchanceté présente dans le cœur des hommes, la déloyauté qui s'y cache [...], et ils n'ont pas d'autorité pour enquêter sur elles. Ils se bornent à condamner les délits commis, sans se préoccuper de ceux qui ont été imaginés [...]. Mais moi, oui, je le peux! Je suis l'Autorité, Je suis la Loi, j'ordonne la vie ou la mort, la liberté, l'emprisonnement ou l'exil. Je peux en finir avec eux tous ou refréner ma colère envers certains, à ma guise ${ }^{23} \ldots$

Cette diatribe finale peut certes évoquer la figure de tyrans de l'Antiquité (Thrasybule de Milet ou Néron) mais elle joue également sur l'anachronisme délibéré, préfigurant les leaders totalitaires du XX ${ }^{e}$ siècle, Staline, Hitler ou Mao.

\section{Le statut de l'artiste}

21 Cette circularité évoque également l'œil de l'artiste, fonctionnant comme une caméra vis-à-vis des «faits divers » successifs dont il est le témoin/rapporteur. Autant les scènes de portrait sont empreintes de solennité et de cérémonie dans le cadre figé de 
l'atelier, dominé par d'immenses tableaux, autant les "choses vues ${ }^{24}$ » à travers les artères et les places de la capitale donnent lieu par la suite à une transe créatrice, fébrile et instinctive. La série interroge sur le statut d'un artiste d'exception, manifeste dès le prologue (réitéré à chaque épisode avec d'infimes variations de champ). Cela est visible à la position même du peintre dans cette séquence répétitive, prostré, solitaire et environné de ténèbres, à son visage figé, comme à la musique (roulements de tambour sinistres, évoquant un glas), mais surtout à ses propos, soulignés par des effets de style (anaphore et emploi d'un champ lexical significatif, signalé en gras dans la citation qui suit). Il s'agit néanmoins d'une citation apocryphe, puisqu'elle n'apparaît nulle part dans la correspondance et les autres écrits conservés de Goya ${ }^{25}$ :

GOYA. Ferdinand VII m'a pardonné, ce qui ne signifie pas que je sois innocent. Désormais plus personne n'est innocent, quand il en a vu autant, et tout ce que j'ai $\mathbf{v u}$ ! J'ai vu comment les idées les plus nobles de Lumières, liberté et progrès devenaient des lances, des sabres et des baïonnettes, signes d'une nouvelle et barbare volonté de domination. J'ai vu commettre des incendies, des sacs et des viols au nom d'un nouvel ordre qui n'a guère apporté que la substitution de l'infâme garrot à la potence. J'ai vu qu'à la barbarie répondait l'atrocité, que la haine ne suscitait que la haine en retour, et que le sang engendrait seulement le sang, toujours plus assoiffé de vengeance. Autour de moi, il n'y a pas eu d'idée élevée ou digne qui ne se soit finalement traduite par la torture, la séquestration ou la trahison. Le Juste ne trouverait de réconfort à son angoisse dans rien de ce que mes yeux ont vu. Il n'y a pas d'innocence en moi, ni dans mon époque ; peut-être seulement dans mes œuvres, reflet de l'épouvante ${ }^{26}$.

Goya est d'abord montré comme un précurseur des reporters de guerre, dont les estampes seraient aussi fidèles que leurs photographies. Plusieurs légendes des Desastres vont dans ce sens: "Yo lo vi (Je l'ai vu)» $\left(n^{\circ} 44\right)$ et « $Y$ eso también (Et cela aussi) » ( $\left.n^{\circ} 45\right)$. En réalité, ces dessins ne sont quasiment jamais des témoignages directs $^{27}$. À l'exception d'une allusion possible à l'exploit d'Agustina de Aragón (remplacer un artilleur mourant et canonner une colonne d'assaut impériale), il n'existe pas d'évocations spécifiques du premier siège de Saragosse, alors que le chef des assiégés, José Palafox, l'avait invité à célébrer l'héroïsme de la ville. Goya affirme d'ailleurs à Marchena que les Français ont détruit les œuvres qu'il a consacrées à ce sujet (1.3). La véracité de sa représentation des suppliciés français d'Andujar est encore plus sujette à caution : les atrocités commises envers les hommes du général Dupont dans la Manche et en Andalousie orientale durant l'été de 1808 ne sont attestées que par des témoins impériaux...

Homme bien informé, clairvoyant et curieux de son temps, il apparaît doté d'une capacité prophétique, notamment dans la séquence de la procession (1.1) et surtout durant la discussion avec Marchena (1.3). Face à l'optimisme forcené de l'afrancesado, il se borne à marmonner plusieurs fois "des marées de sang "... La série en fait également un pionnier de l'entente entre les peuples et du pacifisme, dont l'échec (la mort en exil à Bordeaux) sera relayé par l'engagement hugolien en faveur des États-Unis d'Europe à partir de septembre 1849. Le visage horrifié du jeune Victor, alors âgé de neuf ans (1.4) devant les cadavres exposés, suggère que sa traversée de l'Espagne en guerre fut à l'origine de ce choix politique. Dans le même sens, la série s'attache à magnifier le titre universaliste attribué postérieurement à la série d'estampes, et non celui que Goya lui avait initialement donné : Funestes conséquences de la guerre sanglante que l'Espagne mena chez elle contre Bonaparte... 
Enfin, on peut discerner dans sa longue tirade apocryphe, reprise supra, une "culpabilité du survivant», renforcée par l'allusion aux Justes, renvoyant à l'expérience personnelle de Semprún à Buchenwald, et qui accentuerait la dimension visionnaire de l'œuvre goyesque. Comme l'écrit Primo Levi, «survivre sans avoir renoncé à rien de son propre monde moral, à moins d'interventions puissantes et directes de la chance, n'a été donné qu'à un tout petit nombre d'êtres supérieurs, de l'étoffe des saints et des martyrs ${ }^{28}$."

Mais il s'agit également d'un homme de compromis, que sa charge met au service du maître du moment, même si la série minore clairement cet aspect. Elle occulte ainsi qu'il fut le protégé de Godoy, le favori détesté de Charles IV. Elle passe aussi sous silence son ralliement au roi Joseph, récompensé par l'octroi de la décoration de l'Ordre royal d'Espagne, le 11 mars $1811^{29}$, comme sa participation à une commission chargée du choix de 50 des meilleurs tableaux de l'École espagnole à offrir à l'Empereur. Au contraire, elle s'efforce de le présenter constamment comme un sage, un partisan du juste milieu face aux exaltés des deux partis. Le dernier épisode signale cependant qu'il fut une des rares personnes graciées par Ferdinand VII en 1814, après avoir évoqué la haine populaire à son encontre. Alors qu'il s'affaire à réaliser ses grands tableaux patriotiques, un des carreaux de son atelier est brisé par une pierre, et on entend la foule vociférer « Traitre! » et «Afrancesado!» (1.6).

\section{Une vision renouvelée de la guerre d'Indépendance?}

Au sein de la vaste et inégale filmographie napoléonienne, Los Desastres de la guerra ont fait l'objet d'appréciations très favorables, soulignant son sérieux et ses efforts constants d'objectivité ${ }^{30}$. Ces dernières sont cependant pour la plupart antérieures au renouvellement historiographique entraîné par l'approche puis la célébration du Bicentenaire du conflit, de sorte qu'il convient de les questionner.

\section{Un contexte particulièrement favorable}

Cette série de Mario Camus s'inscrit pleinement dans le contexte de consolidation de la démocratie dans la péninsule ibérique. Les échecs de la conspiration Galaxie en 1978 et du putsch madrilène du 23 février 1981 marquaient la fin des ingérences politiques de l'armée espagnole, cycle entamé justement durant la Guerre d'Indépendance. Le conflit avait en effet suscité l'éclosion des pronunciamientos ${ }^{31}$, qu'ils soient de tendance réactionnaire (La Romana en octobre 1809, Elio en mai 1814) ou libérale (Ballesteros en octobre 1812, Espoz y Mina en septembre 1814).

Cette co-production franco-espagnole s'inscrit aussi dans le contexte de la candidature de l'Espagne à l'entrée dans le Marché Commun, acceptée non sans mal en juin 1985. Elle s'appuie aussi, tout en contribuant à la conforter, sur la proximité des gouvernements socialistes récemment parvenus au pouvoir dans les deux pays, même si le PSOE, repris en main par Felipe González, se distinguait nettement des positions idéologiques du PS, du moins avant le «tournant de la rigueur » imposé par François Mitterrand.

Ces conditions propices tendaient à légitimer le Grand Empire comme un précédent à l'Union européenne, aux dépens de l'image traditionnelle de Napoléon en conquérant 
insatiable. Elles permirent donc de réaliser une coproduction culturelle de prestige sur un sujet épineux, démarche qui aurait été impensable une décennie auparavant. La présence de Semprún, binational et intellectuel engagé de renom $^{32}$, parmi les scénaristes facilita l'entreprise. En fait, il incarna le versant afrancesado face aux positions patriotes défendues par Azcona, Chamorro assurant la médiation, de sorte que le scénario fut le fruit de constants compromis ${ }^{33}$. On peut d'ailleurs y déceler, écho des positions contrastées des auteurs, l'impact des débats agitant alors la gauche européenne, entre messianisme communiste excusant les moyens utilisés au nom des fins recherchées et limites humanistes opposées au volontarisme politique ${ }^{34}$. La première alternative renvoie aux positions de Napoléon et de Marchena, convaincus du potentiel performatif de l'idéologie, la seconde à l'attitude modérée du roi Joseph et de Goya, mais aussi aux doutes croissants du général Hugo sur le bien-fondé de l'intervention française en Espagne.

Dès lors, il ne pouvait plus être question du «nous contre eux " caractéristique des films et séries antérieurs ${ }^{35}$, même si la francophobie traditionnelle avait été progressivement édulcorée durant le franquisme, notamment à cause des impératifs touristiques. Jesús Maroto souligne en effet que si les films "officiels" espagnols comme Lola la Piconera (Luis Lucia, 1951) ou Venta de Vargas (Enrique Carlos Salaberry, 1958) persistaient à diffuser un message intégriste et antilibéral, les personnages de soldats et surtout d'officiers français y étaient dépeints de façon beaucoup plus favorable ${ }^{36}$. Les seconds, notamment, par leur courage et leur caractère chevaleresque, s'avéraient même capables de séduire l'héroïne espagnole et de la détourner - très provisoirement - de son devoir... Outre un ressort dramatique, on le voit, reconnaître la valeur de l'adversaire permettait aussi de magnifier la résistance espagnole à l'envahisseur. Mais les considérations économiques l'emportaient de plus en plus: outre le développement touristique, les films historiques supposaient un budget toujours plus élevé, qu'une seule nation (ou firme) pouvait difficilement assumer. D'où la place croissante des coproductions européennes à partir des années 1960-1970 dans la filmographie élaborée par Jesús Maroto : Los tres etcéteras del Coronel (Claude Boissol, 1960), La Guerrilla (Rafael Gil, 1972), La Guerrillera (Pierre Kast, 1982)... Los desastres de la guerra, première série coproduite sur le sujet, s'inscrit donc dans une continuité des pratiques, qui a sans doute favorisé l'adoption du projet, malgré - ou grâce à - son ambition inédite.

Pourtant, on peut se demander si le manichéisme n'est pas inhérent au genre des séries historiques par souci de dramatisation. De fait, si les relations franco-espagnoles sont décrites de façon généralement nuancée (voir infra), la série se caractérise par une nette anglophobie. Le choix en revint sans aucun doute à la partie française; il n'empêche que ce sentiment correspondait à une réalité, encore partagée de nos jours par une partie du public espagnol ${ }^{37}$. Wellington apparaît ainsi arrogant, calculateur, très méfiant à l'égard des guérilleros et réactionnaire ${ }^{38}$, mais aussi particulièrement fourbe en ourdissant la capture de l'Empecinado dont la réputation lui porte ombrage (1.5). Le $5^{\mathrm{e}}$ épisode suggère que sous son apparence de libérateur, il s'agit en fait d'un occupant aussi odieux, sinon pire, que les Français... Divers événements en ce sens sont évoqués par l'Empecinado: sa politique de "terre brûlée » en Estrémadure et au Portugal, le sac de Badajoz après sa "libération " par les troupes anglo-portugaises ${ }^{39}$; la caméra montre en outre la destruction de la Fabrique de porcelaine de Madrid, 
présentée comme un acte, parmi d'autres, de sabotage délibéré au profit de l'économie britannique.

Enfin, la série profite du discrédit de la vulgate nationale-catholique du conflit, qui avait connu son apogée à l'orée des années 1960, avec le colloque organisé à Saragosse en mars/avril 1959, conformiste dans son approche et particulièrement orientét ${ }^{40}$, et l'essai du sulfureux juriste Carl Schmitt, Théorie du partisan (1962). Elle s'appuie en revanche sur la nouvelle historiographie libérale, principalement menée par Miguel Artola, un historien moderniste converti au progressisme marxisant en abordant l'époque contemporaine ${ }^{41}$. On peut même soutenir qu'elle en constitue un calque pour les principaux thèmes (voir infra). Cette vulgarisation des thèses de l'historien basque est d'autant plus facile qu'il existe alors un relatif consensus libéral sur la mémoire du conflit : les historiens révisionnistes ne publieront leurs premières œuvres qu'après la diffusion de la série en Espagne et en France.

\section{Guérilla, contre-guérilla, Napoléonides et afrancesamiento : une approche renouvelée?}

S'agissant de la représentation de guérilla, à travers l'exemple récurrent de l'Empecinado, on peut considérer que la série n'innove guère. Elle reprend pour l'essentiel, et jusque dans ses moindres détails, la thèse développée par Miguel Artola dans un article aussi influent que contestable : la naissance en Espagne, vers 1809, de la guerre révolutionnaire ${ }^{42}$. Il s'agirait d'un mouvement spontané, nourri par la désertion des troupes régulières (en l'occurrence quelques fugaces recrues de l'armée espagnole constituée par Joseph dès juillet 1808, 1.2), et équipé sur l'ennemi. Son chef méprise toute perspective de butin ou d'extorsion (il ne veut l'argent de ses victimes que pour payer ses hommes et respecte les bijoux de la parente du maréchal Moncey qu'il a capturée, 1.2), il se montre légaliste lors de son évasion. Il convient de signaler ici que l'impact du phénomène auprès du public espagnol a été amplifié par le choix de l'interprète du leader insurgé, Sancho Gracia, très populaire pour ses rôles antérieurs de « bandit d'honneur patriote » dans les séries Curro Jiménez (1977-1978) et La máscara negra $(1982)^{43}$.

La volonté de résistance est présentée comme unanime, y compris parmi les quelques partisans du «roi intrus » comme l'illustre l'anecdote (authentique) de l'enfant du corregidor de Madrid, D. Dámaso de la Torre. Il est présenté au Roi par son père, afrancesado notoire, qui a choisi pour lui un habit de la Garde Civique, institution de sécurité créée par l'occupant sur le modèle de la Garde Nationale. Le roi l'interrogeant sur son épée jouet, il répond fièrement qu'elle lui servira à "matar franceses ", à tuer des Français (1.4)... Dès lors, les guérilleros, en parfaite et constante symbiose avec la population, apparaissent invincibles. Sur les huit embuscades et escarmouches représentées dans le téléfilm, ils en remportent sept $(87,5 \%)$ et ne sont surpris par le général Hugo que le jour même de la défaite décisive des Français à Vitoria, le 21 juin 1813... Comme le note à juste titre Jesús Maroto ${ }^{44}$, cet " exploit » tardif est d'ailleurs imaginaire. Il occulte surtout les succès antérieurs remportés contre les partidas (bandes insurgées) par Suchet et Soult, voire les prémices de la contre-insurrection contemporaine ${ }^{45}$.

Or, la supériorité matérielle des occupants est constamment soulignée par la caméra. Ainsi, les unités d'élite sont clairement surreprésentées au sein des forces 
napoléoniennes: cuirassiers et carabiniers semblent former «l'essentiel» de la cavalerie, au détriment des chasseurs et hussards. En revanche, la fréquence des dragons à l'écran correspond à la réalité ${ }^{46}$. Mais l'infanterie impériale ne se résume pas à une étroite minorité de grenadiers en bonnets d'ours (1 régiment sur les 200 que compte la Grande Armée en 1813) ! En outre, si l'on excepte les uhlans polonais (décisifs lors de la victoire à Somosierra) et le cas spécifique du Royal-Étranger, rassemblement cosmopolite de déserteurs et de traînards, les troupes sociales (Italiens, Allemands de la Confédération du Rhin, Napolitains, Hollandais...), pourtant très présentes dans cette " sale guerre ", ne sont jamais représentées.

De ce fait, la riposte française n'en paraît que plus dérisoire ; elle s'avère aussi classique que contre-productive, traduisant désarroi et impuissance (1.3 et 1.4) : prise d'otages, exécutions sommaires et massacres, incendies de localités complices ou même à titre d'exemple dissuasif, recours récurrent à la torture (flagellation, estrapade, brûlures au fer rouge.... ${ }^{47}$. L'originalité des pratiques du général Hugo n'apparaît guère, malgré son expertise proclamée. Il n'hésite pas à se «salir les mains ", en effet, même s'il inculque une stricte discipline à son régiment, le Royal-Étranger, et recourt parfois à la clémence afin de déconcerter l'ennemi...

Enfin, et surtout, les guérilleros constituent l'avant-garde de la révolution : la partida obéit à des règles de démocratie directe, comme le montre le refus collectif de l'offre de ralliement du général Hugo (1.4). Ils sont également les propagandistes zélés de la Constitution, à l'instar de l'Empecinado lisant publiquement ses décrets aux habitants de Tembleque, dans la Manche (1.5). De même, c'est sans doute un hasard si tous les autres chefs de bande présentés (Francisco Abad «Chaleco », Manuel Hernández « El Abuelo », Juan Palarea «El Médico » et Pedro Villacampa Maza de Lizana, 1.5) ou simplement évoqués (Jaúregui "El Pastor », 1.4) dans la série sont des libéraux, dont beaucoup paieront de leur vie leur combat contre l'absolutisme, après $1814^{48}$... Pourtant, la guérilla s'avéra aussi un terreau des plus favorables pour les futurs leaders ultras et carlistes $^{49}$, comme le curé Merino, Francisco Longa, le baron d'Eroles, José Ignacio de Uranga, etc.

Je ne m'étendrai guère sur la figure de Napoléon, déjà commentée de façon satisfaisante $^{50}$ : la série distingue l'homme (manipulateur, très autoritaire, goujat avec les femmes) et le politique (bourreau de travail, progressiste, réformateur sincère) de façon novatrice.

La guerre est simplement pour lui le moyen de réaliser son dessein politique soumise aux lois françaises dont il est sûr qu'elles seules sont bonnes ${ }^{51}$.

Si elle reconnaît la véracité de son désir de régénérer l'Espagne (abolition de l'Inquisition, des droits féodaux et des douanes intérieures par les décrets de Chamartín, 1.3) a fortiori face à l'indolence et à la sottise des Bourbons d'Espagne, la série souligne aussi son rapide désintérêt pour ce pays. Dès la fin 1810, ce n'est plus qu'un théâtre d'opération périphérique selon son confident - et ministre de la Police Savary (1.4).

Son frère aîné Joseph, suscite un portrait beaucoup plus favorable, très éloigné de l'image caricaturale de "Pepe Botellas» diffusée par les médias patriotes ${ }^{52}$, mais annonçant les analyses récentes de divers historiens, y compris espagnols ${ }^{53}$. Réformiste, conciliateur et conscient de l'impasse que constitue l'usage de la seule force, il apparaît précocement désabusé sur la réalité de son pouvoir, mais aussi quelque peu « fainéant » 
et geignard. Il semble surtout très isolé, réduit à un cénacle de courtisans «napolitains » - Miot de Melito, les généraux Guye et Hugo et leurs familles - au risque de constituer un «laager (camp retranché) français», selon la formule de Michael Broer $^{54}$, à Madrid. Ce risque ethnocentriste est d'ailleurs illustré par le projet de traduction de pièces de Molière par Marchena, afin «d'éclairer » la société espagnole (1.4). D'autres « proches » du roi ne sont que les agents de son frère, comme Savary et l'ambassadeur La Forest, et observent de près ses actes. Napoléon n'avait-il pas ordonné à cet égard: "Recommandez à $\mathrm{M}$. de Laforest la plus grande surveillance et la plus grande attention, et de vous instruire exactement de tout ce qui viendrait à sa connaissance $^{55} »$.

41 De fait, l'État espagnol de Joseph Bonaparte semble n'être qu'une coquille vide, menacée tant par l'insurrection générale de ses « sujets » que par la pesante tutelle de Napoléon et la nécessité prioritaire de pourvoir à l'entretien des armées d'occupation. Son impuissance est flagrante, à l'instar des mesures dérisoires contre la famine, adoptées dans sa capitale au cours du printemps de 1812 (1.5). Ici, les scénaristes n'ont pas mis à profit les divers travaux précurseurs du Catalan Joan Mercader Riba abordant l'administration du « roi intrus » dès 1959 et culminant avec son étude monumentale, publiée peu après la première diffusion de la série ${ }^{56}$. On chercherait en vain dans les différents épisodes une allusion, par exemple, à l'intense travail de réforme législative mené entre 1809 et 1811, concrétisé par l'adoption de près de 370 décrets. De même, l' afrancesamiento est réduit à sa plus stricte expression, là encore vulgate d'un ouvrage pionnier de $\mathrm{M}$. Artola ${ }^{57}$, et de sa distinction sommaire entre ralliés sincères et juramentados (assermentés) amorphes. Le roi ne compte guère de partisans espagnols : quelques courtisans (sa maîtresse volontiers frondeuse, la marquise de Montehermoso, et le général Morla, un renégat) et une poignée d'exaltés sinon d'illuminés, comme l'anticlérical bravache Marchena; les réticences prêtées à Goya sont données comme l'opinion majoritaire de l'intelligentsia.

Quelques rares allusions laissent pourtant deviner aux spectateurs les plus attentifs une réalité sociale beaucoup plus vaste: divers notables municipaux soucieux du maintien de l'ordre (comme celui qui dénonce aux Français l'Empecinado emprisonné par ordre du général patriote Cuesta, 1.2), ou des aristocrates opportunistes saluant le nouveau souverain (1.2). Il faut y ajouter le souvenir nostalgique du ralliement de l'Andalousie, dont la conquête au printemps de 1810 ne fut qu'une promenade militaire (1.4) et où durant quelques semaines, Joseph put se sentir vraiment roi ${ }^{58}$. L'explication me paraît ici à chercher du côté espagnol: refuser la moindre apparence de guerre civile au conflit antinapoléonien, qui rappellerait à l'évidence de mauvais souvenirs à une société durablement traumatisée par les événements de 1936-1939 ${ }^{59}$.

\section{Conclusion}

Cette série constitue donc une indéniable rupture esthétique, marquant la disparition définitive des espagnolades (corridas, flamenco, duels à la navaja...) longtemps dominantes dans la filmographie du conflit. Surabondante dans les productions péninsulaires, cette tendance n'épargna pas les films hollywoodiens à gros budget : le meilleur exemple en est Orgueil et passion (Stanley Kramer, 1957), piteuse adaptation d'un fort beau roman de Cecil S. Forester. Voir Frank Sinatra en cordonnier analphabète jouer les toreros improvisés ou Sophia Loren se déhancher 
approximativement afin d'encourager les insurgés, sous l'œil hagard de Cary Grant, reste un grand moment de cinéma...

À cette tradition, Mario Camus oppose une recherche d'authenticité dans la présentation des principaux personnages historiques, tant par un maquillage très réussi que par la sélection d'anecdotes révélatrices de leur psychologie, par petites touches successives. Il se montre également très pédagogique - et économe - dans la restitution des événements, en allant à l'essentiel et/ou en recourant à l'exemple : les résultats des batailles de Medina de Rioseco, Bailén, Arapiles, sont annoncés par des messagers, tandis que l'opposition entre libéraux et ultras parmi les patriotes de Cadix est abordée par le biais d'un débat enflammé aux Cortes, puis d'une discussion de taverne (1.5).

La série se détache aussi par son souci de la restitution du travail de Goya, passant par des sanguines et des pastels préparatoires, comme des décors. C'est moins vrai pour les costumes, dans la mesure où elle utilise surtout des uniformes de parade (et toujours impeccables, s'agissant des Français), peu appropriés au quotidien misérable des belligérants en Espagne. Ainsi, les forces napoléoniennes sont montrées de façon trop flatteuse, de manière à magnifier la victoire espagnole : la série reprend ici un ressort de la production franquiste consacrée à la Guerra de la Independencia. Enfin, la seule bataille montrée à l'écran, Somosierra, a sacrifié le souci de vraisemblance historique au profit de l'esthétique et des effets spéciaux (neige et brouillard) ${ }^{60} \ldots$ Reste que la performance est d'autant plus remarquable que le coût du tournage fut inférieur à 2 millions d'euros, contre 40 pour la coproduction internationale Napoléon (Yves Simoneau, 2002), d'une durée équivalente et qui suscita de nombreuses controverses ${ }^{61}$.

Qu'en dire sur la dimension proprement historique? On l'a vu, la série adhère pleinement aux thèses de Miguel Artola formulées dans les années 1950-1960 (et ressassées encore de nos jours par l'éminent historien et ses élèves). Or, selon moi, ce dernier a surtout réactualisé la vision libérale élaborée dès les années 1830 , qui reposait entre autres sur une « légende dorée » du mouvement guérillero, puis sur une relative réhabilitation des afrancesados. Aujourd'hui, Los desastres de la guerra s'avère donc largement dépassée sur le plan historiographique. En tant que vulgarisation intelligente, "pacifiée » et relativement nuancée, la mini-série constitue néanmoins une incitation à la curiosité, un appel à l'approfondissement des connaissances; il a sans nul doute contribué à réveiller l'intérêt pour ce conflit fondateur de l'Espagne contemporaine. En tout cas, le fait de l'avoir vu adolescent compta parmi les facteurs qui motivèrent le choix de mon sujet de thèse ${ }^{62}$.

D'autre part, « les œuvres de fiction cinématographique [et télévisuelle] expriment la vulgate d'une époque ${ }^{63}$.» Divers anachronismes, inconscients ou délibérés de la part des scénaristes, s'intègrent à la narration. J'ai déjà mentionné «la culpabilité du survivant " exprimée par Goya dans le prologue ou l'assimilation finale du borné Ferdinand VII à un leader totalitaire. Il en va de même pour la mauvaise conscience du général Hugo, confronté à une lutte révolutionnaire qu'il a lui-même mené en Vendée contre les «Blancs »; tenté de lui accorder une " paix des braves» (1.3), il en arrive à imaginer l'ultime affrontement avec l'Empecinado comme un duel homérique ou un tournoi chevaleresque (1.6). Elle ne peut qu'évoquer le dilemme des officiers européens immergés dans les guerres de décolonisation: un tel rapprochement sous-tendait d'ailleurs déjà l'évolution hispanophile du Béarnais Saint-Armou, officier napoléonien et héros de la trilogie romanesque (1957-1963) de Joseph Peyré ${ }^{64}$. Plus globalement, la 
série traduit assez fidèlement l'état d'esprit majoritaire de l'opinion espagnole du début de la démocratie: pacifisme consensuel, identité nationale ouverte, et sentiment rétroactif d'une victoire à la Pyrrhus en 1814, signant la naissance des deux Espagne, l'une noire et l'autre rouge ${ }^{65}$.

Sur ce dernier point, on peut finalement se demander si cette production, en dépit de son pessimisme affiché, ne finit pas par exercer une influence cathartique. Le rappel de la victoire espagnole sur Napoléon, conforté par la survalorisation des troupes impériales et la sous-estimation parallèle du rôle de Wellington, réhabilite un idéal patriotique dévoyé par le franquisme (et potentiellement menacé par les prémices de la mise en place des Communautés autonomes). Il peut aussi contribuer à déculpabiliser les Espagnols du temps (et ceux de 1936 ?), contrecoup médiatique du "pacte d'oubli » assumé par la transition démocratique. En effet, l'occasion manquée - libérale bien plus que napoléonienne, dans la mesure où la volonté de régénération impériale, déjà non dépourvue d'ambiguïtés, est systématiquement contredite à l'écran par la rapacité et la brutalité des occupants - est in fine imputée aux machinations de Ferdinand VII et de sa camarilla réactionnaire (Montijo, Escoiquiz, Elio...) ainsi qu’à Wellington.

\section{BIBLIOGRAPHIE}

ALEXANDER Don W., Rod of Iron. French Counterinsurgency Policy in Aragon during the Peninsular War, Wilmington, Scholarly Resources, 1985.

ALONSO LóPEZ Jesús, « 1808-1950 : Agustina de Aragón, estrella invitada del cine histórico franquista ", éd. Joaquín Álvarez Barrientos, La Guerra de la Independencia en la cultura española, Madrid, Siglo XXI de España, 2008, p. 379-400.

ÁlVAREZ BARRIENTOS Joaquín, « Sobre la "construcción” de la imagen de Goya : algunos usos y abusos ", in Goya y su contexto, Saragosse, Institución Fernando el Católico, 2013, p. 17-38.

ÁlVAREZ JUNCO José, « La invención de la Guerra de la Independencia », Studia Historica. Historia contemporánea, 12, 1994, p. 75-99.

ÁlVAREZ JUNCO José, « El nacionalismo español como mito movilizador. Cuatro guerras », éd. Rafael Cruz et Manuel Pérez Ledesma, Cultura y movilización en la España contemporánea, Madrid, Alianza Editorial, 1998, p. 35-67.

ALLIES Paul, « Jorge Semprun : une autobiographie politique », Pôle Sud, 1, 1994, p. 11-21.

ARTOLA Miguel, Los afrancesados, Madrid, Alianza Editorial, 1989 [1953].

ARTOLA Miguel, « La guerra de guerrillas. Planteamientos estratégicos en la Guerra de la Independencia », Revista de Occidente, II, 10, 1964, p. 12-43.

BROERS Michael, «Les Français au-delà des Alpes : le laager français de 1796 à 1814 », in Nicolas Bourguinat et Sylvain Venayre (éds.), Voyager en Europe de Humboldt à Stendhal. Contraintes nationales et tentations cosmopolites 1790-1840, Paris, Nouveau Monde, 2007, p. 71-94. 
CAMPORESI Valeria, «The Past in the Present. Reflections on the Imaginary Construction of the $19^{\text {th }}$ Century Spanish War for Independence in the Series Los desastres de la Guerra (M. Camus, TVE, 1983)", Cine y... Revista de estudios interdisciplinarios sobre el cine en español, 1-1, 2008, p. 86-97.

CASTILLA Alberto, Wellington y la contrarrevolución en España, Mérida, Editora Regional de Extremadura, 2012.

CEBALloS-ESCALERA Alfonso de et Almudena de ARTEAga, La Orden Real de España (1808-1813), Madrid, Ediciones Montalbo, 1997.

CHANTERANNE David et Isabelle veYRAT-MASSON, Napoléon à l'écran. Cinéma et télévision, Paris, Nouveau Monde/Fondation Napoléon, 2003.

COCHET François, La Grande Guerre. Fin d'un monde, début d'un siècle, Paris, Perrin/Ministère de la Défense, 2014.

DÉROZIER Claudette, « La caricature antinapoléonienne », Les Espagnols et Napoléon, Aix-en-

Provence, PU de Provence, 1984, p. 197-204.

DELAPLANCHE Jérôme et Axel SANSON, Peindre la guerre, Paris, Nicolas Chaudun, 2009.

DELAY Pierre, Joseph Peyré (1892-1968). L'homme et son œuvre : à la rencontre des héros, Biarritz, J \& D Éditions, 1992.

DÍAZ TORREJÓN Francisco Luis, José Napoleón I en el sur de España. Un viaje regio por Andalucía (eneromayo 1810), Cordoue, CajaSur Publicaciones, 2008.

DUfOUR Gérard, « Le roi philosophe », Mélanges de la Casa de Velázquez, 38-1, 2008, p. 53-70.

DUFOUR Gérard, « 1813 : la situación político-militar en España desde la visión francesa », in Miguel Ángel Sánchez Gómez (dir), La Guerra de la Independencia en Castro Urdiales. 11 de mayo de 1813, Gobierno de Cantabria/Ayuntamiento de Castro Urdiales, 2015, p. 21-37.

DWYER Philip G., « Violence and the Revolutionary and Napoleonic Wars : Massacre, Conquest and the Imperial Enterprise », Journal of Genocide Research, 15-2, 2013, p. 117-131.

ESDAILE Charles J., « The Spanish guerrilla : Heroes or Villains ? », History Today, 4, 1988, p. 28-35. ESDAILE Charles J., « Hacia doscientos años. Reflexiones sobre un largo Bicentenario », éd. Arsenio García Fuertes, Francisco Carantoña Álvarez et Oscar González García, Más que una guerra : Astorga y el noroeste de España en el conflicto peninsular (1808-1814), Universidad de León, 2014, p. 195-204.

GASSIER Pierre, Goya, témoin de son temps, Fribourg, Office du Livre, 1983.

GODICHEAU François, «L'ombre portée de la guerre civile sur le $\mathrm{XX}^{\mathrm{e}}$ siècle espagnol », éd. Pietro Casaunaro et Valeria Galimi, Le XX $X^{e}$ siècle des guerres, Paris, Editions de l'Atelier, 2004, p. 451-461.

KASPER Michael, « Los guerrilleros de la Francesada durante el Trienio Constitucional », Trienio, Ilustración y Liberalismo, 23, 1994, p. 61-102.

LAFON Jean-Marc, L'Andalousie et Napoléon. Contre-insurrection, collaboration et résistances dans le midi de l'Espagne (1808-1812), Paris, Nouveau Monde/Fondation Napoléon, 2007.

LAFON Jean-Marc, « Contre-guérilla ou contre-insurrection ? La politique de pacification de Soult en Andalousie (1810-1812) », Ocupació y resistència en la Guerra del Francès (1808-1814), Barcelone, Museu d'Història de Catalunya, 2007, p. 541-551.

LAFON Jean-Marc, « Del Dos de Mayo madrileño a los pontones de Cádiz : violencias francesas y españolas a principios de la Guerra de la Independencia », éd. Francisco Acosta Ramírez et Marta 
Ruiz Jiménez, Baylen 1808-2008. Bailén : su impacto en la nueva Europa del siglo XIX y su proyección futura, Universidad de Jaén, 2009, p. 105-128.

LAFON Jean-Marc, « La contre-insurrection, une invention française ? Généalogie d'une pratique (1792-1849) », Insurrection, contre-insurrection, que nous apprend l'Histoire ?, Cercle d'Etude académique de Défense, Mende, 28 janvier 2011.

LAFON Jean-Marc, « Confrontation, résistance et politisation. La Guerre d'Indépendance (1808-1814), une rupture cruciale pour l'Espagne? », éd. Laurent Bourquin, Philippe Hamon, Alain Hugon et Yann Lagadec, La politique par les armes. Conflits internationaux et politisation (XVXIX ${ }^{e}$ siècle), Rennes, PUR, 2013, p. 183-200.

LASPRA RODRíGUEZ Alicia, « Del Mito a la Historia : las perfidias de Albión en la Península », Desperta Ferro, Especiales 2, 2012, p. 20-24.

LEVI Primo, Si c'est un homme, Paris, Pocket, 2004 [1947].

MAROTO DE LAS HERAS Jesús, Guerra de la Independencia. Imágenes en cine y televisión, Madrid, Cacitel, 2007.

MATTEI Jean-Pierre (éd.), Napoléon et le cinéma. Un siècle d’images, Ajaccio, Piazzola, 1998.

MELON Miguel Ángel, « Badajoz (1811-1812). La resistencia en la frontera », éd. Gonzalo Butrón et Pedro Rújula, Los sitios en la Guerra de la Independencia : la lucha en las ciudades, Madrid, Silex, 2012, p. 215-248.

MERCADER RIBA Joan, José Bonaparte rey de España. Estructura del Estado español bonapartista, Madrid, CSIC, 1983.

MORENO ALONSO Manuel, José Napoleón. Un rey republicano en el trono de España, Madrid, La Esfera de los Libros, 2008.

OLIVER Mike, « El sitio de Badajoz », Cuadernos del Bicentenario, número extraordinario, 2013, p. 73-83.

OTERO VÁZQUEZ Eva, « Goya-Saura-Storaro : tres artistas en el Séptimo Arte », Revista Latente. Revista de historia y estética del audiovisual, 7, 2011, p. 107-121.

OTERO VÁZqUEZ Eva, « Una época convulsa de la sociedad española a través de la figura de Goya en el cine », Goya y su contexto, Saragosse, Institución Fernando el Católico, 2013, p. 211-220.

PEIRÓ MARTíN Ignacio, La Guerra de la Independencia y sus conmemoraciones (1908, 1958 y 2008). Un estudio sobre las políticas del pasado, Saragosse, Institución Fernando el Católico, 2008.

PEIRÓ MARTín Ignacio, « Días de ayer en la historiografía española. La Guerra de la Independencia y la "conversión liberal" de los historiadores ", éds. Pedro Rújula et Jordi Canal, Guerra de ideas. Política y cultura en la España de la Guerra de la Independencia, Madrid, Marcial Pons, 2012, p. 445-479.

PETITEAU Natalie, Napoléon Bonaparte, la Nation incarnée, Paris, A. Colin, 2015.

RÚjuLA Pedro, « Realismo y contrarrevolución en la Guerra de la Independencia », Ayer, 86, 2012, p. 45-66.

SÁNCHEZ TOSTADO Luis Miguel, «El uso penitenciario del castillo de Santa Catalina », Boletín del Instituto de Estudios Giennenses, 176-1, 2000, p. 31-74.

SAÑUDO Juan José, Base de datos sobre las unidades militares en la Guerra de la Independencia española, Madrid, Ministerio de Defensa, 2007. 
SOUBEYROUX Jacques, Goya politico, Madrid, FEHME, 2013.

TODOROv Tzvetan, Goya à l'ombre des Lumières, Paris, Flammarion, 2011.

TONE John L., The Fatal Knot. The Guerrilla War in Navarre and the Defeat of Napoleon in Spain, Chapel Hill, The University of North Carolina Press, 1994.

TROUVÉ Mathieu, « La culture du pronunciamiento en Espagne », Parlement [s]. Revue d'histoire politique, 12, 2009, p. 87-99.

ULZURRUN ZABALZA Germán, « Origen documental del apodo “Pepe Botellas” y su contexto histórico », Cuadernos del Bicentenario, 26, 2016, p. 175-200.

\section{ANNEXES}

\section{Filmographie}

El Dos de Mayo (José Buchs, 1927)

El Abanderado (Eusebio Fernández Ardavín, 1943)

La maja del capote (Fernando Delgado, 1943)

María Antonia la Caramba (Antonio Ruiz Castillo, 1950)

Lola la Piconera (Luis Lucia, 1951)

Le Fils de Caroline chérie (Jean Devaivre, 1955)

Orgueil et passion (Stanley Kramer, 1957)

La Tirana (Juan de Orduña, 1958)

Venta de Vargas (Enrique Carlos Salaberry, 1958)

The naked Maja (Henry Koster, 1959)

Los tres etcéteras del Coronel (Claude Boissol, 1960)

Goya, historia de una soledad (Nino Quevedo, 1970)

Goya l'hérétique (Goya-oder der arge Weg der Erkenntnis, Konrad Wolf, 1972)

La Guerrilla (Rafael Gil, 1972)

Curro Jiménez (TVE, 1977-1978)

La Ruche (La Colmena, Mario Camus, 1982)

La máscara negra (José Antonio Jiménez-Rico et Al., 1982)

La Guerrillera (Pierre Kast, 1982)

La máscara negra (TVE, 1982)

Los Desastres de la guerre / Guerrilla ou les désastres de la guerre (TVE et Antenne 2, 1983)

Goya à Bordeaux (Goya en Burdeos, Carlos Saura, 1999)

Volaverunt (Juan José Bigas Luna, 1999) 
Napoléon (TF1, 2002)

Les Fantômes de Goya, (Goya's Ghosts, Milos Forman, 2006)

\section{NOTES}

1. A l'heure où nous écrivons, l'ensemble de la série est visible sur Youtube: https:// www.youtube.com/watch?v=2jS2JPd_xTc

2. Selon El País du 6 juin 1983.

3. Valeria Camporesi, «The Past in the Present. Reflections on the Imaginary Construction of the $19^{\text {th }}$ Century Spanish War for Independence in the Series Los desastres de la Guerra (M. Camus, TVE, 1983)", Cine y... Revista de estudios interdisciplinarios sobre el cine en español, 1-1, 2008, p. 86 [p. 86-97]. 4. Jean-Marc Lafon, «Confrontation, résistance et politisation. La Guerre d'Indépendance (1808-1814), une rupture cruciale pour l'Espagne?», La politique par les armes. Conflits internationaux et politisation (XV-XIX $X^{e}$ siècle), éd. Laurent Bourquin, Philippe Hamon, Alain Hugon et Yann Lagadec, Rennes, PUR, 2013, p. 183-200.

5. Quelques rares films muets mis à part, tels La mère du moine. Épisode de la guerre d'Espagne (Louis Feuillade, 1909) ou Le message de l'Empereur (Georges-André Lacroix, 1912) qui se bornent à exploiter la légende impériale, selon Jesús Maroto de las Heras, Guerra de la Independencia. Imágenes en cine y televisión, Madrid, Cacitel, 2007, p. 45 et 48.

6. Soit les deux capitales rivales (Madrid et Cadix), Avila (premier gouvernement du général Hugo et cadre des prémices de son projet de contre-guérilla), et deux champs de bataille (Somosierra et Vitoria).

7. Maroto de las Heras, p. 382-390 et 395-400.

8. Qui voyait dans la guerre un soulèvement spontané et unanime pour défendre «le Roi, la religion et la patrie ", en rejetant toutes les influences étrangères qui avaient corrompu le pays durant le XVIII ${ }^{\mathrm{e}}$ siècle.

9. Don W. Alexander, Rod of Iron. French Counterinsurgency Policy in Aragon during the Peninsular War, Wilmington, Scholarly Resources, 1985 ; Charles J. Esdaile, « The Spanish guerrilla : Heroes or Villains?", History Today, 4, 1988, p. 28-35; John L. Tone, The Fatal Knot. The Guerrilla War in Navarre and the Defeat of Napoleon in Spain, Chapel Hill, The University of North Carolina Press, 1994.

10. José Álvarez Junco, «La invención de la Guerra de la Independencia », Studia Historica. Historia contemporánea, 12, 1994, p. 75-99, et «El nacionalismo español como mito movilizador. Cuatro guerras ", in Cultura y movilización en la España contemporánea, éd. Rafael Cruz \& Manuel Pérez Ledesma, Madrid, Alianza Editorial, 1998, p. 35-67.

11. Respectivement El Dos de Mayo (José Buchs, 1927), El Abanderado (Eusebio Fernández Ardavín, 1943), La maja del capote (Fernando Delgado, 1943), La Tirana (Juan de Orduña, 1958), María Antonia la Caramba (Antonio Ruiz Castillo, 1950), Goya, historia de una soledad (Nino Quevedo, 1970) ; The naked Maja (Henry Koster, 1959) ; Goya-oder der arge Weg der Erkenntnis (Konrad Wolf, 1972); et La máscara negra (José Antonio Jiménez-Rico et Al., 1982), selon Maroto de las Heras, p. 30 et Eva Otero Vázquez, « Goya-Saura-Storaro : tres artistas en el Séptimo Arte », Revista Latente. Revista de historia y estética del audiovisual, 7, 2011, p. 110 [p. 107-121].

12. Eva Otero Vázquez, « Una época convulsa de la sociedad española a través de la figura de Goya en el cine ", Goya y su contexto, Saragosse, Institución Fernando el Católico, 2013, p. 211-220.

13. Notamment Tzvetan Todorov, Goya à l'ombre des Lumières, Paris, Flammarion, 2011 et Jacques Soubeyroux, Goya politico, Madrid, FEHME, 2013.

14. Jérôme Delapalanche, Axel Samson, Peindre la guerre, Paris, Nicolas Chaudun, 2009, p. 115-119. 
15. Joaquín Álvarez Barrientos, «Sobre la "construcción" de la imagen de Goya : algunos usos y abusos ", in Goya y su contexto, op. cit., p. 19 et 21-22 [p. 17-38].

16. Présente au début de chaque épisode, elle clôt aussi le dernier.

17. Gérard Dufour, « 1813 : la situación político-militar en España desde la visión francesa », in La Guerra de la Independencia en Castro Urdiales. 11 de mayo de 1813, éd. Miguel Ángel Sánchez Gómez, Gobierno de Cantabria/Ayuntamiento de Castro Urdiales, 2015, p. 28 [p. 21-37].

18. Pierre Gassier, Goya, témoin de son temps, Fribourg, Office du Livre, 1983, p. 95.

19. Jean-Marc Lafon, « Del Dos de Mayo madrileño a los pontones de Cádiz : violencias francesas y españolas a principios de la Guerra de la Independencia ", in Baylen 1808-2008. Bailén : su impacto en la nueva Europa del siglo XIX y su proyección futura, éd. Francisco Acosta Ramírez et Marta Ruiz Jiménez, Universidad de Jaén, 2009, p.105-128; Philip G. Dwyer, «Violence and the Revolutionary and Napoleonic Wars : Massacre, Conquest and the Imperial Enterprise ", Journal of Genocide Research, 15-2, 2013, p. 117-131.

20. Jesús Alonso López, «1808-1950 : Agustina de Aragón, estrella invitada del cine histórico franquista ", La Guerra de la Independencia en la cultura española, éd. Joaquín Álvarez Barrientos, Madrid, Siglo XXI de España, 2008, p. 379-400.

21. Maroto de las Heras, p. 51, 113, 404 et 408-409.

22. Ibid., p. 381.

23. Propos de Ferdinand VII au général Elio, à la fin du dernier épisode. Traduction personnelle.

24. Au sens hugolien, puisque le jeune Victor constitue le jalon suivant dans un autre mouvement souterrain de l'intrigue, cette fois plus ténu mais linéaire et porteur de progrès, conçu par les scénaristes (au moins Semprún et Chamorro), voir infra.

25. Camporesi, p. 89.

26. Seconde partie du générique, tirade de Goya. Traduction personnelle.

27. Todorov, p. 137-139.

28. Primo Levi, Si c'est un homme (1947), Paris, Pocket, 2004, p. 142.

29. Alfonso de Ceballos-Escalera, Almudena de Arteaga, La Orden Real de España (1808-1813), Madrid, Ediciones Montalbo, 1997, p. 147.

30. Napoléon et le cinéma. Un siècle d'images, éd. Jean-Pierre Mattéi, Ajaccio, Piazzola, 1998, p. 295 ; David Chanteranne, Isabelle Veyrat-Masson, Napoléon à l'écran. Cinéma et télévision, Paris, Nouveau Monde/Fondation Napoléon, 2003, p. 133 ; Maroto de las Heras, p. 26.

31. Voir Mathieu Trouvé, "La culture du pronunciamiento en Espagne », Parlement [s] Revue d'histoire politique, 12, 2009, p. 87-99.

32. Paul Alliès, "Jorge Semprun : une autobiographie politique ", Pôle Sud, 1, 1994, p. 11-21.

33. Information communiquée par Jesús Maroto dans son courriel du 29 janvier 2015, d'après une confidence de Mario Camus.

34. Chanteranne, Veyrat-Masson, p. 134-135.

35. El Abanderado (Eusebio Fernández Ardavín, 1943), El Verdugo (Enrique Giménez Bascuas, 1947) et El Tambor del Bruch (Ignacio F. Iquino, 1948) font preuve d'une virulente francophobie ; ils sont également bâtis sur le rapprochement explicite de l'insurrection de 1808 et du putsch nationaliste de 1936, cf. Maroto de las Heras, p. 75, 79, 85 et 89.

36. Maroto de las Heras, p. 18, 155 et 212.

37. Alicia Laspra Rodríguez, "Del Mito a la Historia : las perfidias de Albión en la Península », Desperta Ferro, Especiales 2, 2012, p. 20-24. Pour sa part, Charles J. Esdaile note toujours la prégnance dans l'opinion espagnole de cette perception de l'alliance anglaise comme "perfide et égoïste", "Hacia doscientos años. Reflexiones sobre un largo Bicentenario ", éd. Arsenio García Fuertes, Francisco Carantoña Álvarez et Oscar González García, Más que una guerra: Astorga y el noroeste de España en el conflicto peninsular (1808-1814), Universidad de León, 2014, p. 198 [p. 195-204]. 
38. Même s'il occulte ses qualités de tacticien et sa ténacité, le portrait est assez fidèle, notamment pour sa constante et active opposition à la Constitution espagnole, partagée par son frère, l'ambassadeur Wellesley, cf. Alberto Castilla, Wellington y la contrarrevolución en España, Mérida, Editora Regional de Extremadura, 2012.

39. Miguel Ángel Melón, "Badajoz (1811-1812). La resistencia en la frontera ", Los sitios en la Guerra de la Independencia : la lucha en las ciudades, éd. Gonzalo Butrón \& Pedro Rújula, Madrid, Silex, 2012, p. 242-246 [p. 215-248] ; Mike Oliver, « El sitio de Badajoz », Cuadernos del Bicentenario, número extraordinario, 2013, p. 76-77 [p. 73-83]

40. Ignacio Peiró Martín, La Guerra de la Independencia y sus conmemoraciones (1908, 1958 y 2008). Un estudio sobre las políticas del pasado, Saragosse, Institución Fernando el Católico, 2008, p. 182-183, 206-211.

41. Ignacio Peiró Martín, "Días de ayer en la historiografía española. La Guerra de la Independencia y la "conversión liberal" de los historiadores ", in Guerra de ideas. Política y cultura en la España de la Guerra de la Independencia, éd. Pedro Rújula et Jordi Canal, Madrid, Marcial Pons, 2012, p. 466-467 [p. 445-479].

42. Miguel Artola, «La guerra de guerrillas. Planteamientos estratégicos en la Guerra de la Independencia », Revista de Occidente, II, 10, 1964, p. 12-43.

43. Maroto de las Heras, p. 43.

44. Ibid., p. 396.

45. Jean-Marc Lafon, "Contre-guérilla ou contre-insurrection? La politique de pacification de Soult en Andalousie (1810-1812) ", Ocupació y resistència en la Guerra del Francès (1808-1814), Barcelone, Museu d'Història de Catalunya, 2007, p. 541-551 ; « La contre-insurrection, une invention française ? Généalogie d'une pratique (1792-1849) », Insurrection, contre-insurrection, que nous apprend l'Histoire?, Cercle d'Etude académique de Défense, Mende, 28 janvier 2011, en ligne sur pedagogie.ac-montpellier.fr./hist_geo/ defense/.

46. 26 régiments de cette « infanterie montée » furent déployés à travers la Péninsule, jouant un rôle majeur contre la guérilla, $c f$. Juan José Sañudo, Base de datos sobre las unidades militares en la Guerra de la Independencia española, Madrid, Ministerio de Defensa, 2007.

47. Cette pratique est avérée par divers témoignages et enquêtes concernant les gouverneurs français de Valladolid (Dorsenne) et Lérida (Henriod). L'archéologie a également révélé la présence d'une estrapade dans les cachots du château de Jaén, installée et utilisée par la garnison impériale, $C f$. Luis Miguel Sánchez Tostado, «El uso penitenciario del castillo de Santa Catalina », Boletín del Instituto de Estudios Giennenses, 176-1, 2000, p. 54 [p. 31-74].

48. Michael Kasper, "Los guerrilleros de la Francesada durante el Trienio Constitucional», Trienio, Ilustración y Liberalismo, 23, 1994, p. 61-102.

49. Pedro Rújula, «Realismo y contrarrevolución en la Guerra de la Independencia », Ayer, 86, 2012, p. 45-66.

50. Chanteranne, Veyrat-Masson, p. 134.

51. Natalie Petiteau, Napoléon Bonaparte, la Nation incarnée, Paris, A. Colin, 2015, p. 270.

52. Claudette Dérozier, «La caricature antinapoléonienne ", Les Espagnols et Napoléon, Aix-enProvence, PU de Provence, 1984, p. 197-204. Également Germán Ulzurrun Zabalza, «Origen documental del apodo "Pepe Botellas" y su contexto histórico ", Cuadernos del Bicentenario, 26, 2016, p. 175-200.

53. Gérard Dufour, "Le roi philosophe », Mélanges de la Casa de Velázquez, 38-1, 2008, p. 53-70 ; Manuel Moreno Alonso, José Napoleón. Un rey republicano en el trono de España, Madrid, La Esfera de los Libros, 2008. 
54. Michael Broers, «Les Français au-delà des Alpes : le laager français de 1796 à 1814 ", Voyager en Europe de Humboldt à Stendhal. Contraintes nationales et tentations cosmopolites 1790-1840, éd. Nicolas Bourguinat et Sylvain Venayre, Paris, Nouveau Monde, 2007, p. 71-94.

55. Archives du Ministère des Affaires étrangères, Correspondance de Napoléon avec Champagny, 1785, lettre du 24/04/1810.

56. Joan Mercader Riba, José Bonaparte rey de España. Estructura del Estado español bonapartista, Madrid, CSIC, 1983.

57. Miguel Artola, Los afrancesados (1953), Madrid, Alianza Editorial, 1989, p. 39-41.

58. Francisco Luis Díaz Torrejón, José Napoleón I en el sur de España. Un viaje regio por Andalucía (enero-mayo 1810), Córdoba, CajaSur Publicaciones, 2008.

59. François Godicheau, «L'ombre portée de la guerre civile sur le $\mathrm{XX}^{\mathrm{e}}$ siècle espagnol », Le XX siècle des guerres, éd. Pietro Casaunaro et Valeria Galimi, Paris, Editions de l'Atelier, 2004, p. 451-461

60. Maroto de las Heras, p. 390.

61. Chanteranne, Veyrat-Masson, p. 90.

62. Jean-Marc Lafon, L'Andalousie et Napoléon. Contre-insurrection, collaboration et résistances dans le midi de l'Espagne (1808-1812), Paris, Nouveau Monde/Fondation Napoléon, 2007, p. 17.

63. François Cochet, La Grande Guerre. Fin d'un monde, début d'un siècle, Paris, Perrin/Ministère de la Défense, 2014, p. 461.

64. Pierre Delay, Joseph Peyré (1892-1968). L'homme et l'œuvre : à la rencontre des héros, Biarritz, J \& D Éditions, 1992, p. 151-153.

65. Camporesi, p. 92-94.

\section{RÉSUMÉS}

Les désastres de la guerre, série historique réalisée par Mario Camus en 1982, constitue un projet ambitieux, abordant à la fois un thème brûlant des relations franco-espagnoles et un moment fondateur de l'histoire ibérique, la guerre d'Indépendance contre les troupes napoléoniennes (1808-1814). Construite autour de la personnalité complexe de Goya et de son observation précise et nuancée des événements, il s'agit aussi d'une coproduction hispano-française ambitieuse qui reflète aussi l'histoire troublée de l'Espagne au XXème siècle. La présence parmi les scénaristes de l'intellectuel engagé Jorge Semprun témoigne de la dimension de cette entreprise. Ainsi, l'esthétique et la structure narrative de la série sont particulièrement complexes, selon un aspect circulaire qui en accentue la dimension réflexive. Ensuite, l'œuvre est à la fois révélatrice du tournant historiographique en train de s'opérer vis-à-vis de l'événement, du contexte particulier de la consolidation démocratique et de la candidature au Marché Commun du début des années 1980, et de la mémoire - ou plutôt de l'oubli - des déchirements liés au franquisme dont les racines sont bien plus anciennes.

The Disasters of War, TV Series realized by Mario Camus in 1982, is an ambitious project tackling at once a thorny matter in French-Spanish relationship and a founder moment for Iberian History. Built upon the complex personality of Goya, it's also a Spanish-French production; between the scripwriters, the presence of the committed intellectual Jorge Semprun testify this reality. This work proceeds from a double critic, aesthetic and historical. The first is focalizing about the place 
and the part attributed to Goya, the second analyzes the way which the Series fits into the Spanish (and European) context while proposing a Peninsular War's "new" interpretation.

\section{INDEX}

Mots-clés : Guerre d'Indépendance espagnole (1808-1814), série historique, Goya Francisco de, Semprun Jorge, Camus Mario

Keywords : Peninsular War (1808-1814), period drama, Goya Francisco de, Semprun Jorge, Camus Mario

\section{AUTEUR}

\section{JEAN-MARC LAFON}

Agrégé et docteur en Histoire, ancien boursier de la Fondation Napoléon, Jean-Marc Lafon est chercheur associé de CRISES (université de Montpellier III), délégué de la Commission Française d'Histoire Militaire pour le Languedoc-Roussillon et membre du Foro para el Estudio de la Historia Militar de España.

Il a notamment publié L'Andalousie et Napoléon. Contre-insurrection, collaboration et résistances dans le midi de l'Espagne (1808-1812) (Nouveau Monde, 2007) ; L'Espagne aux XIX $X^{e}$ et XX' siècles (Ellipses, 2007) ; et Guerres et conflits dans le monde au XIX ${ }^{e}$ siècle (1792-1914) (Ellipses, 2013). Ses recherches portent sur la Guerre d'Espagne de 1808-1814, sujet auquel il a consacré une trentaine d'articles et de communications en France et en Espagne (analyse critique des témoignages, adaptation de l'armée napoléonienne à la guérilla, violences extrêmes, traces et mémoires du conflit...), et plus généralement sur le phénomène guerrier à l'époque contemporaine. Outre plusieurs études consacrées au génocide arménien - notamment dans Du génocide des Arméniens à la Shoah. Typologie des massacres du XX siècle (Privat, 2015) -, il a participé au Dictionnaire de la France Libre (R. Laffont, 2010), ainsi qu'à L'Encyclopédie de la Seconde Guerre mondiale, à paraître chez le même éditeur fin 2015. 